\title{
Efektivitas Penggunaan Anoda Korban Paduan Seng Pada Pelat Baja Kapal AISI E 2512 Terhadap Laju Korosi Di Dalam Media Air Laut
}

\author{
Lia Pongsapan ${ }^{1)}$, Amin Suhadi ${ }^{2)}$ \\ Program Studi Teknik Mesin Fakultas Teknologi Industri \\ Universitas Balikpapan \\ Jalan Pupuk Raya PO BOX 335 Balikpapan \\ Email: lia_ftiuniba@yahoo.com
}

\begin{abstract}
Hull plates are part of construction of the first affected by sea water corrosion. Until now, one way to protect the hull plate from corrosion is cathodic protection often used is the sacrificial anode system. Sacrificial anode types used in this study is zinc alloy.

This research method is field observation and laboratory experiments. Object of observation is a wire laying vessel ship, which under replating repairs and replacement of sacrificial anode. Test speciment for experimental laboratory is a steel plate AISI E 2512, two kinds of zinc alloy sacrificial anode products are different (the product A contain $99.80 \%$ of zinc, the product B contain $99.20 \%$ of zinc). The results showed that the zinc alloy sacrificial anode mounted on the hull plate can work optimally with the corrosion rate of ship hull plates of $0.073 \mathrm{~mm} /$ year and in compliance with applicable standards and met the eligibility safe condition. Results of corrosion testing in the laboratory can also prove that most optimal performance is the product of zinc alloy sacrificial anode A, because it has the of the lowest vessel steel plate at $0.0662 \mathrm{~mm} / \mathrm{year}$ in the horizontal direction and average corrosion rate $0.0689 \mathrm{~mm} /$ year in the vertical direction.
\end{abstract}

Key words: Ship steel plate, Zinc alloy scacrificial anode, Corrosion rate

\begin{abstract}
Abstrak
Pelat lambung kapal adalah bagian konstruksi yang pertama kali terkena korosi air laut. Sampai saat ini salah satu cara untuk melindungi pelat lambung kapal dari serangan korosi adalah dengan metoda proteksi katodik. Metoda proteksi katodik yang sering dipakai adalah sistim anoda korban. Jenis anoda korban yang digunakan dalam penelitian ini adalah paduan seng.

Metodologi penelitian ini adalah observasi lapangan dan eksperimen laboratorium. Objek observasi adalah kapal Wire Laying Vessel yang menjalani reparasi penggantian pelat dan anoda korban. Spesimen uji untuk eksperimen laboratorium adalah pelat baja kapalAISI E 2512, dua macam produk anoda korban paduan seng yang berbeda yaitu (produk A mengandung 99,80\% seng, produk B mengandung 99,20\% seng. Hasil perhitungan dari observasi lapangan menunjukkan bahwa anoda korban paduan seng produk A yang dipasang pada lambung kapal telah bekerja secara optimal dengan laju korosi rata - rata sebesar 0,073 mm/tahun sehingga telah sesuai dengan standar kelayakan dan memenuhi syarat aman. Hasil pengujian korosi di laboratorium membuktikan bahwa diantara kedua anoda korban paduan seng yang dipasang pada pelat baja kapal AISI E 2512 ternyata yang mempunyai kinerja paling optimal adalah anoda korban paduan seng produk A, dengan laju korosi rata - rata pada pelat baja paling rendah yaitu 0,0662 mm/tahun arah horisontal (arah memanjang kapal) dan laju korosi rata - rata arah vertikal 0,0689 mm/tahun.
\end{abstract}

Kata kunci : Pelat Baja Kapal, Anoda korban paduan seng, Laju korosi

\footnotetext{
1) Mahasiswa Program Studi Magister Teknik Mesin, Universitas Pancasila

2) Dosen Program Studi Magister Teknik Mesin, Universitas Pancasila
} 


\section{Pendahuluan}

Korosi pada pelat lambung kapal mengakibatkan turunnya kekuatan dan umur pakai kapal. Untuk menghindari kerugian akibat korosi dalam air laut diperlukan perlindungan korosi pada pelat lambung kapal. Salah satu cara untuk melindungi pelat lambung kapal dari korosi air laut adalah dengan metoda proteksi katodik menggunakan sistim anoda korban. Perlindungan anoda korban mempunyai kelebihan yaitu : lebih sederhana, stabil dan biaya perawatan relatif rendah [16].

Penelitian ini bertujuan mengetahui efektivitas penggunaan anoda korban paduan seng sebagai proteksi katodik dan mengetahui kebutuhan anoda korban untuk memperlambat laju korosi serta menentukan posisi pemasangan yang optimal pada pelat baja di dalam media air laut. Kualitas anoda korban paduan seng dipengaruhi oleh komposisi paduan anoda, ada dua jenis anoda korban paduan seng yang digunakan di perusahaan kapal Balikpapan, sebagai cathodic protection pada lambung kapal yang mempunyai komposisi paduan berbeda.

Kemampuan proteksi anoda korban paduan seng terhadap pelat baja disebabkan karena adanya perbedaan komposisi paduan tetapi adakalanya di lapangan ditemui pelat lambung kapal yang ter korosi dikarenakan kurangnya kebutuhan berat dan jumlah anoda korban yang dipasang serta posisi pemasangan yang kurang tepat, oleh karena itu penelitian ini mengamati tentang kinerja dan kebutuhan pemasangan dua jenis anoda korban paduan seng produk A dan produk B sebagai cathodic protection pelat lambung kapal serta pengaruhnya terhadap laju korosi untuk kapal yang beroperasi di perairan Balikpapan.

\section{Metode Penelitian}

Metodologi penelitian ini terdiri atas dua bagian yaitu : observasi lapangan dan eksperimen laboratorium. Objek observasi adalah kapal Wire Laying Vessel yang menjalani reparasi penggantian pelat dan anoda di galangan kapal. Observasi dilakukan dengan mengukur ketebalan pelat lambung kapal pada titik-titik tertentu menggunakan alat ukur ultrasonic test [13]. Data hasil observasi yang berupa tebal pelat lambung kapal dianalisa untuk menentukan laju korosi pada pelat kapal [17]

$$
C R=\frac{K \times W}{A \times D \times T}
$$

Keterangan :

$\mathrm{CR}=$ Laju korosi $(\mathrm{mm} / \mathrm{th})$

$\mathrm{W}=$ Massa yang terkorosi (gram)

$\mathrm{A}=$ Luas tercelup $\left(\mathrm{cm}^{2}\right)$

$\mathrm{K}=8.76 \times 10^{4}$

$\mathrm{T}=$ Waktu (jam)

$\mathrm{D}=\operatorname{Densitas}\left(\mathrm{gram} / \mathrm{cm}^{3}\right)$

Metode untuk menentukan jumlah anoda korban paduan seng yang dipasang pada pelat lambung kapal berdasarkan luas permukaan basah (wetted surface area). Wetted surface area merupakan rancang bangun luas permukaan lambung kapal yang tercelup di dalam air laut. [8].

Tabel.1. Desain Arus Rata-rata Berdasarkan Kedalaman Iklim

\begin{tabular}{|c|c|c|c|c|}
\hline \multirow[b]{2}{*}{$\begin{array}{l}\text { Kedalaman } \\
\text { (m) }\end{array}$} & \multicolumn{4}{|c|}{ Desain arus densitas (rata - rata) dalam $\mathrm{A} / \mathrm{m}^{2}$} \\
\hline & $\begin{array}{l}\text { Tropical } \\
\left(>20^{\circ} \mathrm{C}\right)\end{array}$ & $\begin{array}{c}\text { Sub- } \\
\text { Tropical } \\
\left(12-20^{\circ} \mathrm{C}\right)\end{array}$ & $\begin{array}{c}\text { Beriklim } \\
\text { sedlang } \\
\left(7-12^{\circ} \mathrm{C}\right)\end{array}$ & $\begin{array}{l}\text { Sangat } \\
\text { dingin } \\
\left(<7^{0} \mathrm{C}\right)\end{array}$ \\
\hline $0 \leq 30$ & 0.070 & 0.080 & 0.100 & $0.120^{(1)}$ \\
\hline$>30$ & 0.060 & 0.070 & 0.080 & 0.100 \\
\hline
\end{tabular}


Area individu $(A c)$ tiap unit yang diproteksi dikalikan dengan desain arus densitas (ic), dan faktor kerusakan lapisan $(f c)$, diperoleh [10] :

\section{Ic $\square \square A c \square \square f c \square \square i c$}

Faktor $I c$ adalah permintaan arus, $A c$ area yang akan diproteksi, $f c$ factor kerusakan lapisan dan ic faktor desain arus densitas, mengacu pada Tabel.2. Area yang diproteksi dapat dihitung dengan [10] :

$$
A c \square \square \square 2 T \square \square B \square \square \square L b p \square \square p
$$

Keterangan :

$$
\begin{aligned}
\text { Lbp } & =\text { Panjang antara garis tegak }(\mathrm{m}) \\
\mathrm{T} & =\text { Sarat air }(\mathrm{m}) \\
\mathrm{B} & =\text { Lebar Kapal }(\mathrm{m}) \\
\mathrm{p} & =\text { Faktor kapal WLV nilainya } 0,85
\end{aligned}
$$

Untuk desain katodik rata-rata dan terakhir faktor kerusakan pelapis dihitung dengan memperhatikan desain umur.

$$
F c=k_{1}+k_{2} \times t_{f}
$$

Jika dihitung nilainya lebih dari $1, \mathrm{fc}=$ 1 harus digunakan di dalam desain. Desain umur sistem katodik proteksi melebihi dari

\begin{tabular}{|c|c|c|c|c|}
\hline \multirow[b]{2}{*}{$\begin{array}{c}\text { Kedalaman } \\
\text { (m) }\end{array}$} & \multicolumn{4}{|c|}{ Kategori Pelapis } \\
\hline & $\begin{array}{c}\mathrm{I} \\
\left(\mathrm{k}_{1}=0.1\right) \\
\mathrm{k}_{2}\end{array}$ & $\begin{array}{c}\text { II } \\
\left(\mathrm{k}_{1}=0.05\right) \\
\mathrm{k}_{2}\end{array}$ & $\begin{array}{c}\text { III } \\
\left(\mathbf{k}_{1}=0.02\right) \\
k_{2}\end{array}$ & $\begin{array}{c}\text { IV } \\
\left(\mathrm{k}_{1}=0.02\right) \\
\mathrm{k}_{2}\end{array}$ \\
\hline $0 \leq \leq 30$ & 0.10 & 0.03 & 0.015 & 0.012 \\
\hline$>30$ & 0.05 & 0.02 & 0.012 & 0.012 \\
\hline
\end{tabular}
sistem pelapis, fc rata-rata dihitung menggunakan [10]:

$$
\text { fc rata rata }=1-\frac{\left(1-k_{1}\right)^{2}}{2 k_{2} t_{f}}
$$

Tabel 2. Konstanta (k1 dan k2) Untuk Perhitungan Kerusakan Pelapis [8].
Eksperimen laboratorium dilakukan dengan metode uji celup [4] untuk memperoleh data korosi yang terjadi pada spesimen uji pelat baja karbon dan anoda korban paduan seng produk A dan produk B. Material pelat kapal adalah pelat marine grade A yang memiliki komposisi kimia setara dengan baja AISI E 2512.

Pelat baja (spesimen uji) dibersihkan untuk menghilangkan kotoran pada pelat baja agar terhindar dari terjadinya korosi awal kemudian dilakukan penimbangan berat sebelum proses uji celup [3]. Ukuran spesimen pelat baja $(170 \mathrm{~mm} \times 40 \mathrm{~mm} \times 10$ $\mathrm{mm}$ )

Spesimen uji anoda korban paduan seng produk A dan produk B. Anoda korban paduan seng yang digunakan yaitu: anoda korban paduan seng produk $\mathrm{A}, \mathrm{Zn}=99,80 \%$ dan anoda korban paduan seng produk B, Zn $=99,20 \%$ [12]. Ukuran anoda korban paduan seng produk A dan produk B yang digunakan untuk memproteksi pelat baja kapal adalah $(20 \mathrm{~mm} \times 10 \mathrm{~mm} \times 5 \mathrm{~mm})$.

Waktu uji celup yang digunakan dalam pengujian korosi adalah 168 jam (1 minggu), 336 jam (2 minggu), 504 jam (3 minggu), 672 jam (4 minggu) [4]. Pengambilan data penurunan berat pelat baja dan anoda korban paduan seng dengan jalan penimbangan spesimen dengan periode tiap 168 jam ( 1 minggu). Laju korosi pada spesimen uji (pelat baja dan anoda korban paduan seng) adalah selisih berat spesimen uji sebelum uji celup dan setelah dilakukan proses uji celup. Data penurunan berat spesimen kemudian dilakukan analisa menggunakan formula [17] untuk mengetahui laju korosi pada spesimen uji.

\section{Pembahasan}

Ukuran utama kapal Elnusa Samudra -1 sebagai berikut :

Length Over All (LOA ) $=46,36 \mathrm{~m}$

Length Between Perpendicular

$$
(\mathrm{LBP})=44,24 \mathrm{~m}
$$


c) Breadth (B) $=9 \mathrm{~m}$

d) Draught $(\mathrm{T})=2,04 \mathrm{~m}$

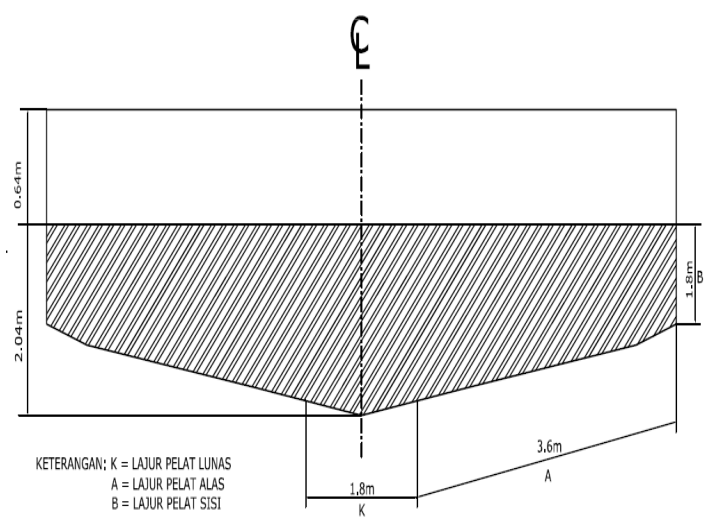

Gambar 1. Potongan melintang Kapal

Pengukuran tebal pelat lambung kapal setelah kapal berlayar 5 tahun di perairan Balikpapan, dilakukan dengan ultrasonict test, sebanyak 108 titik. Observasi dilakukan dengan mengukur ketebalan pelat lambung kapal pada titik-titik tertentu menggunakan alat ukur ultrasonic test [13]. Distribusi titik uji sebagai berikut : (lampiran 3).

a. Lajur pelat lunas : 16 buah titik uji

b. Lajur pelat alas : 64 buah titik uji

(32 kiri dan 32 kanan)

c. Lajur pelat sisi : 28 buah titik uji (28 kiri dan 28 kanan)

Data hasil pengukuran ketebalan pelat kemudian diambil nilai rata-rata sebagai nilai tebal pelat lajur kapal. Tabel 5. berikut memperlihatkan data tebal rata-rata pada masing-masing pelat lajur kapal.

Tabel 5. Data Pengurangan Tebal Pelat Lambung Kapal

\begin{tabular}{|c|c|c|c|c|c|c|}
\hline No & $\begin{array}{c}\text { Lajur Pelat } \\
\text { Lambung Kapal }\end{array}$ & $\begin{array}{c}\text { panjang } \\
\text { L(cm) }\end{array}$ & $\begin{array}{c}\text { Lebar } \\
B(\mathrm{~cm})\end{array}$ & $\begin{array}{c}\text { Luas } \\
\mathrm{A}(\mathrm{cm})\end{array}$ & $\begin{array}{c}\text { Tebal } \\
\text { Awal } \\
(\mathrm{cm})\end{array}$ & $\begin{array}{c}\text { Tebal } \\
\text { Akhir } \\
(\mathrm{cm})\end{array}$ \\
\hline 1 & Lunas kanan kapal & 4530 & 90 & 407700 & 1,2 & 1,164 \\
\hline 2 & Lunas kiri kapal & 4530 & 90 & 407700 & 1,2 & 1,16 \\
\hline 3 & Alas kanan kapal & 4530 & 360 & 1630800 & 1 & 0,96 \\
\hline 4 & Alas kiri kapal & 4530 & 360 & 1630800 & 1 & 0,963 \\
\hline 5 & Sisi kanan kapal & 4530 & 180 & 815400 & 1 & 0,964 \\
\hline 6 & Sisi kiri kapal & 4530 & 180 & 815400 & 1 & 0,969 \\
\hline
\end{tabular}

Gambar 2. Berikut ini merupakan diagram yang memperlihatkan pengurangan nilai tebal masing-masing pelat lajur kapal.

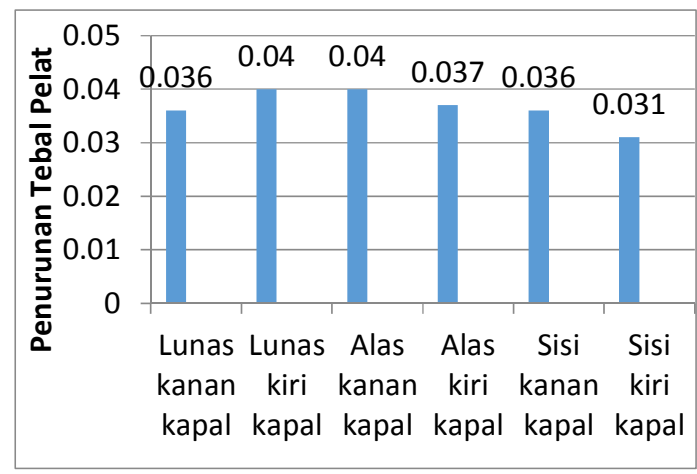

Gambar 2. Diagram Pengurangan tebal Pelat Lajur Kapal

Analisa laju korosi dari data di atas menggunakan formula [17].

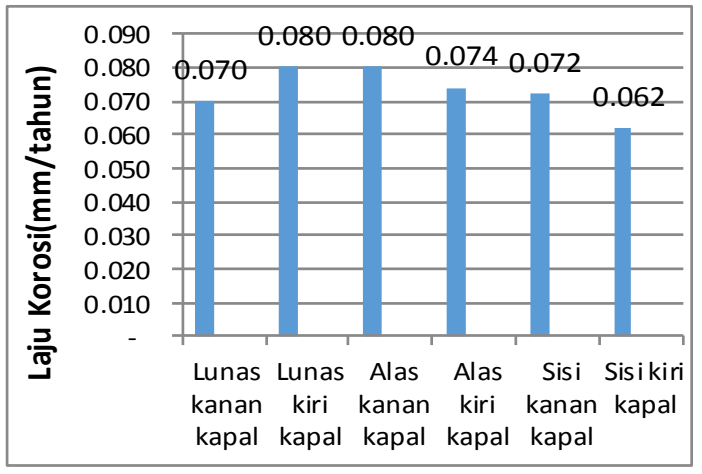

Gambar 3. Laju Korosi Pada Pelat Lambung Kapal

Laju korosi pelat lambung kapal tertinggi pada lajur alas bagian kanan dan lajur lunas bagian kiri sebesar 0,08 $\mathrm{mm} /$ tahun. Laju korosi rata-rata pada pelat lambung kapal 0,073mm/tahun. Laju korosi yang tidak merata disebabkan oleh bio fouling yang menempel di pelat kapal tidak merata dan benturan terjadi antara pelat dengan dasar laut atau dermaga sehingga sebagian pelat kapal rusak.

Kebutuhan anoda korban paduan seng pada kapal dapat dihitung dengan formula [10], diperoleh hasil berikut : 
Gambar 4, berikut merupakan gambar letak Anoda korban paduan seng produk A pada kapal Elnusa Samudra-1

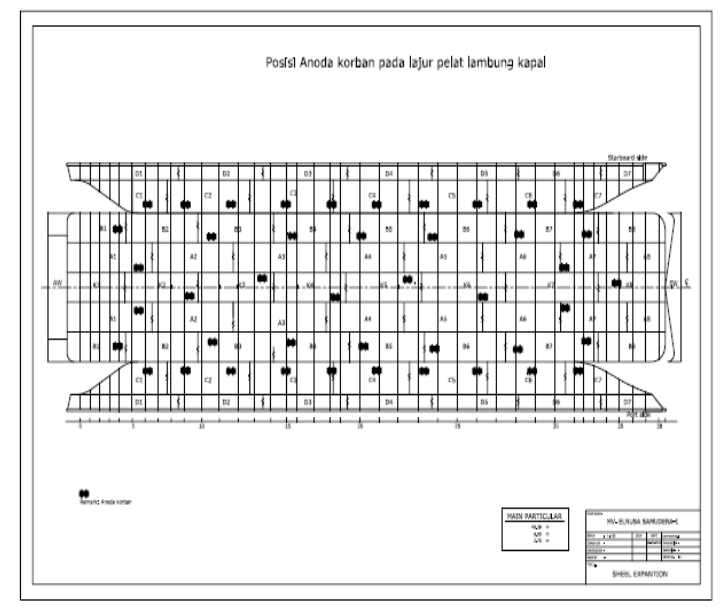

Gambar 4. Letak Anoda Paduan Seng Produk A pada Kapal Elnusa Samudra-1

Tabel 6. Kebutuhan Anoda Korban Paduan Seng Produk A Pada Kapal

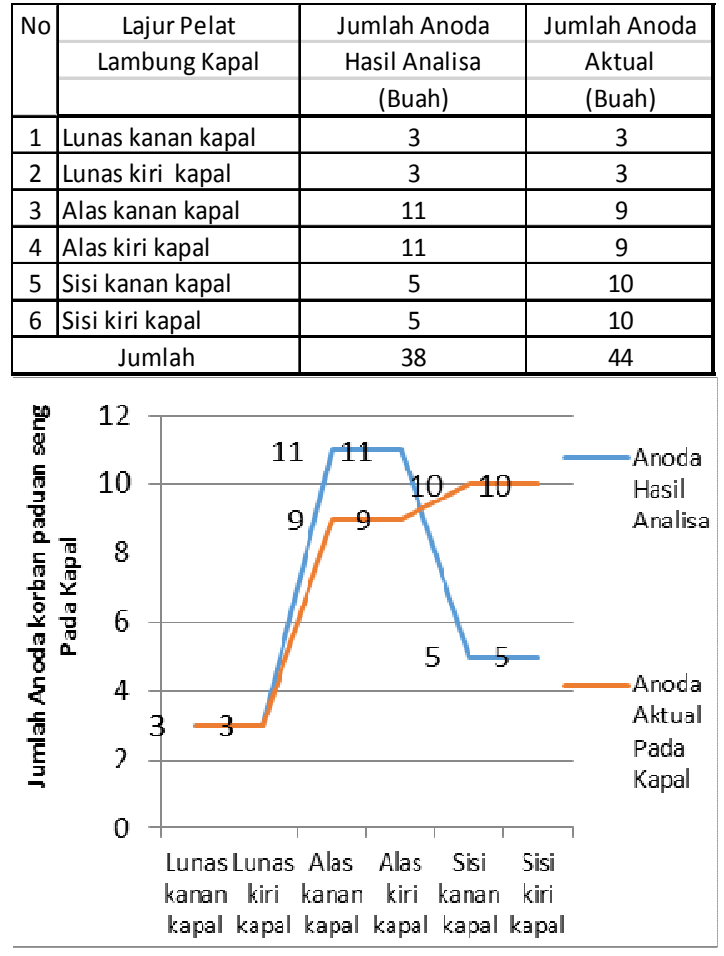

Gambar 5. Diagram Kebutuhan Anoda Korban Seng Pada Lambung Kapal.
Total pelat baja yang digunakan pada percobaan ini adalah 72 spesimen dengan ukuran yang sama yaitu $(170 \mathrm{~mm} \times 40 \mathrm{~mm}$ $\times 10 \mathrm{~mm}$ ) dan spesimen anoda korban paduan seng 48 buah dengan ukuran sama $(20 \mathrm{~mm} \times 10 \mathrm{~mm} \times 5 \mathrm{~mm})$. Anoda korban paduan seng produk A 24 buah dan produk B 24 buah, masing - masing anoda seng (produk A dan produk B) memiliki 12 buah spesimen dipasang horisontal dan vertikal. Data penurunan berat spesimen pelat baja yang di proteksi anoda korban dengan posisi anoda horisontal terhadap pelat baja, sebagai berikut :

Tabel 7. Data Penurunan Berat Pelat Baja dengan Posisi Anoda Horisontal

\begin{tabular}{|c|c|c|c|c|}
\hline No & $\begin{array}{c}\text { Periode } \\
\text { (minggu) }\end{array}$ & $\begin{array}{c}\text { Berat Pelat } \\
\Delta A W R(g r a m)\end{array}$ & $\begin{array}{c}\text { Berat Pelat } \\
\Delta B W R(g r a m)\end{array}$ & $\begin{array}{c}\text { Berat Pelat } \\
\Delta C W R(g r a m)\end{array}$ \\
\hline 1 & $\mathrm{~T} 1$ & 0,1300 & 0,1833 & 0,2433 \\
\hline 2 & $\mathrm{~T} 2$ & 0,2266 & 0,3100 & 0,6133 \\
\hline 3 & $\mathrm{~T} 3$ & 0,3033 & 0,4433 & 0,8533 \\
\hline 4 & $\mathrm{~T} 4$ & 0,4866 & 0,6400 & 1,243 \\
\hline
\end{tabular}

Keterangan :

$\Delta \mathrm{Aw}_{\mathbf{R}}=$ Penurunan berat pelat uji yang diproteksi dengan anoda korban paduan seng produk A dengan posisi horisontal.

$\Delta B w_{R}=$ Penurunan berat pelat uji yang diproteksi dengan anoda korban paduan seng produk $B$ dengan posisi horisontal

$\Delta \mathrm{Cw}_{\mathrm{R}}=$ Penurunan berat pada pelat uji tanpa proteksi katodik

Data penurunan berat spesimen pelat baja yang di proteksi anoda korban dengan posisi anoda vertikal terhadap pelat baja, berikut : 
Tabel 8. Data Penurunan Berat Pelat Baja dengan Posisi Anoda Vertikal

\begin{tabular}{|c|c|c|c|c|}
\hline No & Periode & Berat Pelat & Berat Pelat & Berat Pelat \\
\hline & (minggu) & $\Delta D W R$ (gram) & $\Delta E W R$ (gram) & $\Delta F W R$ (gram) \\
\hline 1 & $\mathrm{~T} 1$ & 0,1400 & 0,1766 & 0,2766 \\
\hline 2 & $\mathrm{~T} 2$ & 0,2633 & 0,3233 & 0,5933 \\
\hline 3 & $\mathrm{~T} 3$ & 0,3200 & 0,4660 & 0,8233 \\
\hline 4 & $\mathrm{~T} 4$ & 0,5400 & 0,6766 & 1,136 \\
\hline
\end{tabular}

Keterangan :

$\Delta \mathrm{Dw}_{\mathbf{R}}=$ Penurunan berat pelat uji yang diproteksi dengan anoda korban paduan seng produk $\mathrm{A}$ dengan posisi vertikal.

$\Delta \mathrm{Ew}_{\mathrm{R}}=$ Penurunan berat pelat uji yang diproteksi dengan anoda korban paduan seng produk B dengan posisi vertikal.

$\Delta \mathrm{Fw}_{\mathrm{R}}=$ Penurunan berat pada pelat uji tanpa proteksi katodik

Laju korosi pada pelat baja hasil eksperimen laboratorium dianalisa menggunakan [17]. Laju korosi spesimen pelat baja yang di proteksi anoda korban dengan posisi anoda horisontal terhadap pelat baja, berikut :

Tabel 9. Laju Korosi Pelat Baja dengan Posisi Anoda Horisontal

\begin{tabular}{|c|c|c|c|c|}
\hline No & $\begin{array}{c}\text { Periode } \\
\text { (minggu) }\end{array}$ & $\begin{array}{c}\text { Laju Korosi CRA } \\
\text { (mm/tahun) }\end{array}$ & $\begin{array}{c}\text { Laju Korosi CRB } \\
\text { (mm/tahun) }\end{array}$ & $\begin{array}{c}\text { Laju Korosi CRC } \\
\text { (mm/tahun) }\end{array}$ \\
\hline 1 & $\mathrm{~T} 1$ & 0,0698 & 0,0984 & 0,1307 \\
\hline 2 & $\mathrm{~T} 2$ & 0,0601 & 0,0832 & 0,1647 \\
\hline 3 & $\mathrm{~T} 3$ & 0,0543 & 0,0794 & 0,1528 \\
\hline 4 & $\mathrm{~T} 4$ & 0,0653 & 0,0859 & 0,1669 \\
\hline \multicolumn{2}{|c|}{ Rata-rata } & 0,0626 & 0,0867 & 0,1538 \\
\hline
\end{tabular}

$\mathrm{C}_{\mathbf{R A}}=$ Laju korosi pada pelat uji yang diproteksi anoda korban paduan seng produk A dengan susunan anoda horisontal

$\mathrm{C}_{\mathrm{RB}}=$ Laju korosi pada pelat uji yang diproteksi anoda korban paduan seng produk B dengan susunan anoda horizontal
$\mathrm{C}_{\mathrm{RC}}=$ Laju korosi pada pelat uji tanpa proteksi katodik

Laju korosi spesimen pelat baja yang di proteksi anoda korban dengan posisi anoda vertikal terhadap pelat baja, berikut ini :

Tabel 10. Laju Korosi Pelat Baja dengan Posisi Anoda Vertikal

\begin{tabular}{|c|c|c|c|c|}
\hline No & $\begin{array}{c}\text { Periode } \\
\text { (minggu) }\end{array}$ & $\begin{array}{c}\text { Laju Korosi CRD } \\
\text { (mm/tahun) }\end{array}$ & $\begin{array}{c}\text { Laju Korosi CRE } \\
\text { (mm/tahun) }\end{array}$ & $\begin{array}{c}\text { Laju Korosi CRF } \\
\text { (mm/tahun) }\end{array}$ \\
\hline 1 & $\mathrm{~T} 1$ & 0,0752 & 0,0948 & 0,1486 \\
\hline 2 & $\mathrm{~T} 2$ & 0,0707 & 0,0868 & 0,1593 \\
\hline 3 & $\mathrm{~T} 3$ & 0,0573 & 0,0835 & 0,1474 \\
\hline 4 & $\mathrm{~T} 4$ & 0,0725 & 0,0909 & 0,1526 \\
\hline \multicolumn{2}{|c|}{ Rata-rata } & 0,0689 & 0,0890 & 0,1520 \\
\hline
\end{tabular}

$\mathrm{C}_{\mathbf{R D}}$ = Laju korosi pada pelat uji yang diproteksi anoda korban paduan seng (produk A) dengan susunan anoda vertikal

$\mathrm{C}_{\mathrm{RE}}=$ Laju korosi pada pelat uji yang diproteksi anoda korban paduan seng kualitas nomor dua (produk B) dengan susunan anoda vertikal

$\mathrm{C}_{\mathrm{RF}}=$ Laju korosi pada pelat uji tanpa proteksi katodik

Posisi pemasangan anoda korban paduan seng pada pelat baja secara horisontal dan posisi vertikal mempengaruhi kinerja anoda.

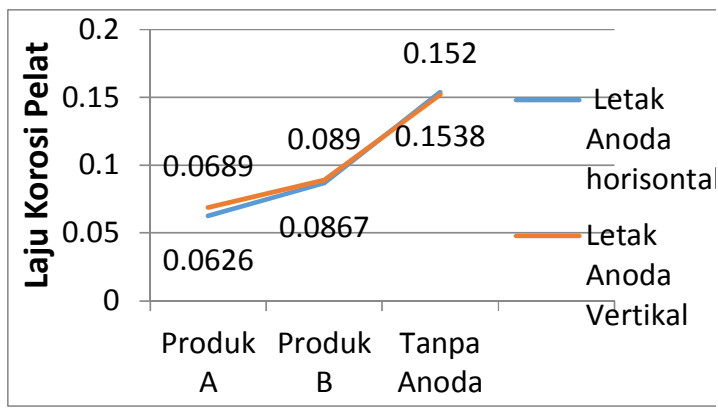

Gambar 6. Perbandingan Laju Korosi Anoda korban paduan seng Posisi Anoda Horisontal dan Vertikal 
Hasil analisa data laboratorium membuktikan bahwa posisi pemasangan anoda korban seng (produk A dan produk B) secara horisontal terhadap pelat baja lebih efektif dibandingkan posisi pemasangan secara vertikal. Laju korosi pada pelat baja yang diproteksi anoda korban paduan seng produk A secara horisontal sebesar 0,0662 $\mathrm{mm} /$ tahun sedangkan proteksi secara vertikal sebesar 0,0689 $\mathrm{mm} /$ tahun. Laju korosi pada pelat baja yang diproteksi anoda korban paduan seng produk B secara horisontal sebesar $0,0867 \mathrm{~mm} /$ tahun sedangkan proteksi secara vertikal sebesar $0,0890 \mathrm{~mm} /$ tahun.

\section{Kesimpulan}

Kesimpulan yang diperoleh dari hasil penelitian ini adalah sebagai berikut :

1. Kebutuhan anoda korban paduan seng pada lambung kapal Elnusa Samudra - 1 sudah memenuhi syarat aman dengan laju korosi rata-rata sebesar 0,073 mm/tahun. Kapal Elnusa Samudra - 1 di proteksi 44 buah anoda korban paduan seng kualitas produk A seberat $8 \mathrm{~kg}$. Total berat anoda korban paduan seng pada kapal Elnusa Samudra - 1 sebanyak $352 \mathrm{~kg}$.

2. Penggunaan anoda korban paduan seng produk A terbukti lebih efektif dibandingkan anoda korban paduan seng produk B. Laju korosi pelat baja yang diproteksi anoda korban paduan seng produk A sebesar $0,0662 \mathrm{~mm} /$ tahun sedangkan laju korosi pelat baja yang diproteksi anoda korban paduan seng produk B lebih tinggi yaitu 0,0867 $\mathrm{mm} / \mathrm{tahun}$.

3. Laju korosi pada pelat baja yang diproteksi anoda korban paduan seng produk A secara horisontal sebesar $0,0662 \mathrm{~mm} /$ tahun sedangkan proteksi vertikal sebesar $0,0689 \mathrm{~mm} /$ tahun .
Laju korosi pada pelat baja yang diproteksi anoda korban paduan seng produk B secara horisontal sebesar $0,0867 \mathrm{~mm} /$ tahun sedangkan proteksi vertikal sebesar 0,0890 $\mathrm{mm} /$ tahun.

\section{Daftar Pustaka}

American Bureau of Shipping (ABS), 2007, Guidance Notes On The Inspection, Maintenance and Application of Marine Coating System,Third Edition, ABS, USA.

[Anggono, Juliana. Citro, Soejono. dan Palapessy, Victor Rizal, 2000, Studi Perbandingan Kinerja Anoda Korban Paduan Aluminium dengan Paduan Seng dalam Lingkungan Air Laut, Jurnal Teknik Mesin, Fakultas Teknologi Petra Industri, Universitas Kristen, Surabaya.

Anonim, 2003, Annual Book of ASTM Standards, Metal Corrosion, Erosion and Wear, Vol 03.02, ASTM International, New York.

Anonim, 2003, Annual Book of ASTM Standards, Standards Practice for the Preparation of Substitute Ocean Water, Vol 11.02, ASTM International, New York.

Antoni, Ahmad, IKM, 1998, Kamus Lengkap Teknik (Inggris - Indonesia), Gitamedia Press, Surabaya.

Benjamin D. Craig, 2006, Corrosion Prevention and Control: A Program Management Guide for Selecting Materials by : Advanced Materials, Manufacturing, and Testing Information Analysis Center (AMMTIAC).

Caridis, P.A, B.Sc, M.Sc, Ph.D MRINA. C. Eng, 1995, Inspection, Repair and Maintenance of Ship Structure, Witherby \& CO. LTD, London 
DNV Recomended Practice RP.B401, 1993, Cathodic Protection Design, Det Norske Veritas Industry Norway AS, Hovik.

Eko Julianto Sasono, 2010, Efektivitas Penggunaan Penggunaan Anoda Korban Paduan Aluminium Pada Pelat baja AISI E 2512 Terhadap laju korosi Di dalam Media Air Laut, Jurnal Teknik Mesin,Program Studi Magister Teknik Mesin,Universitas Diponegoro Semarang.

[Fontana, Mars G, 1986, Corrosion Engineering, 3th Edition, Mc Graw Hill Book Co., New York.

Orozco, R, Canto C.M., Genesca, J, Juarez Islas, J.A, 2005, Electrochemical Characteristics of Al-Zn-Mg Alloys As Sacrificial Anode In Sea Water, In NACE International, Corrosion 2005, Paper No. 05081, Texas, USA.

[PT. Biro Klasifikasi Indonesia, 2004, Regulator for the Corrosion and Coating System, Edition 2004, BKI, Jakarta .
[PT. Biro Klasifikasi Indonesia, 2006, Rules for The Classification and Construction of Seagoing Stel Ships, Edition2006, BKI, Jakarta .

Rustandi, Andi, Johny. W. Soedarsono, 2005, Correlation Efficiency Sacrificial Anode Al-Zn-In Toward Movement of Polarization Curve Using of Potensiodynamic Mothod, In NACE International, Corrosion 2005, Paper No. 05077, Texas, USA.

Sri Widartho, 2001, Karat dan Pencegahannya, PT. Pradnya Paramita, Jakarta.

Tsai, Tai Ming, 1995, Protection of Steel Using Aluminum Sacrificial Anodes in Artificial Seawater, Journal of Marine Science and Technology, Volume 4, No.1, Tahun 1995, halaman $17-21$.

Trethewey, Kenneth, R, B.Sc, Ph.D, C.Chem, MRSC, MCORR.ST, John Chamberlain, 1991, Korosi Untuk Mahasiswa Sains dan Rekayasa, PT. Gramedia Pustaka Utama, Jakarta. 